\title{
The effect of the concentration ratio of Cadmium oxide on the optical properties for Titanium dioxide films
}

\author{
kadhim A.Aadim ${ }^{*}$, Khalaf I. Khaleel $^{* *}$, AymanA.Noori ${ }^{* *}$ \\ "Department of Physics, College of Science, University of Baghdad, Iraq \\ ** Department of Physics, College of education for pure sciences, University of Tikrit, Iraq
}

\begin{abstract}
In this work, $\mathrm{CdO}$ - doped $\mathrm{TiO}_{2}$ thin films with different concentrations $(0.0 \%, 0.1 \%, 0.3 \%, 0.5 \%$ and $1 \%$ ) have been prepared by pulse laser deposition method on glass substrates and annealed in air at $500^{\circ} \mathrm{K}$. The effects of CdO-doping on the optical properties of the TiO2 thin films were studied by UV-visible spectroscopy.The prepared films were characterized by X-ray diffraction. The XRD pattern of the films show a polycrystalline film, with tetragonal structure for $\mathrm{TiO} 2$ and formation of Anatase phase and many peaks(101), (004) and (200) were appear when increasing of CdO concentration a new peak is appearedfor $C d O$, for concentration of $(0.1 \%, 0.3 \%, 0.5 \%$ and $1 \%)$ of $C d O$ for intensities of (111),(200), (220) and (311) with cubic structure. The optical band-gap was also studied from the optical transmittance for the as grown and annealed samples. As expected, the band-gap changes between that for pure $\mathrm{CdO}$ and that for $\mathrm{TiO}_{2}$.
\end{abstract}

Keywords - Optical properties; CdO thin films; PLD, XRD analysis, doped thin films

\section{Introduction}

PLD is one of the most promising techniques for the formation of complex oxide hetero-structures, super-lattices, and well controlled interfaces [1]. This technique generally enables the deposition of highly dense film and has proven its efficiency in growing oxides of complex stoichiometry. Transparent conducting oxide (TCO) thin films have been widely used in solar cells applications. $\mathrm{CdO}$ and $\mathrm{TiO}_{2}$ have high transparency in the visible region of the electromagnetic spectrum and show n-type conductivity, mainly due to oxygen vacancies. With a ranging band gap of 2.2-3.2 eV [2], CdO present the advantage of a low resistivity with respect to the high values obtained for $\mathrm{TiO} 2$, but this exhibits a higher transparency, having a band gap around $3.2 \mathrm{eV}$. It is known that it is difficult to obtain simultaneously a high transmission coefficient in the visible region and good conductivity qualities [3], however a ternary compound which combines these properties in a controlled way may allow the optimization of the window layer. For many years, transparent conductive oxidelayers have been studied extensively because of a widerange of technical applications, for instances as transparentelectrodes in photovoltaic and display devices [4], sensors [5] and so on. Cadmium oxide (CdO) is ntypesemiconductor that crystallizes in the rocksalt structure(FCC) and presents an optical ban-gap of about 2.2 $\mathrm{eV}$ [6].The $\mathrm{CdO}$ films exhibit high transmission in the visible andUV ranges and has high conductivity. These films havebeen used as transparent contact in CuInSe2 [7] and Si [8]solar cells.

\section{ExperimentalWork}

An experimental setup for a typical PLD system is shown in fig. 1. The targets with compositions $\left(\mathrm{TiO}_{2}\right) 1-x(\mathrm{CdO}) x(x=0.00,0.1,0.3,0.5$, and $1.0 \%)$ were synthesized via solid state reaction method. For this purpose, the required proportions of $\mathrm{TiO} 2$ and $\mathrm{CdO}$ in powder form having purity level $99.99 \%$ were mixed together and grinded properly. The thin films were deposited on single crystal silicon $\left(\begin{array}{lll}1 & 0 & 0\end{array}\right)$ substrates using Nd:YAG laser ( $=1064 \mathrm{~nm}, \tau=9 \mathrm{~ns}$, and $\mathrm{El}=700 \mathrm{~mJ}$ ). Nd:YAG laser was focused on to the target surface at an angle of $45^{\circ}$, was placed parallel to the target material at distance of $2 \mathrm{~cm}$. The base pressure $4 \times 10^{-2} \mathrm{mbar}$ was created inside the PLD chamber using rotary pump. A DC Stepper motor was used to rotate and translate the target material during deposition for uniform ablation from the target surface, which helped to avoid the crater formation on the targetes surface. laser pulses were incident on each target to irradiate them during the thin film deposition, and the temperature of the substrate surface was kept at $500 \mathrm{k}$ for all depositions. Post deposition annealing 


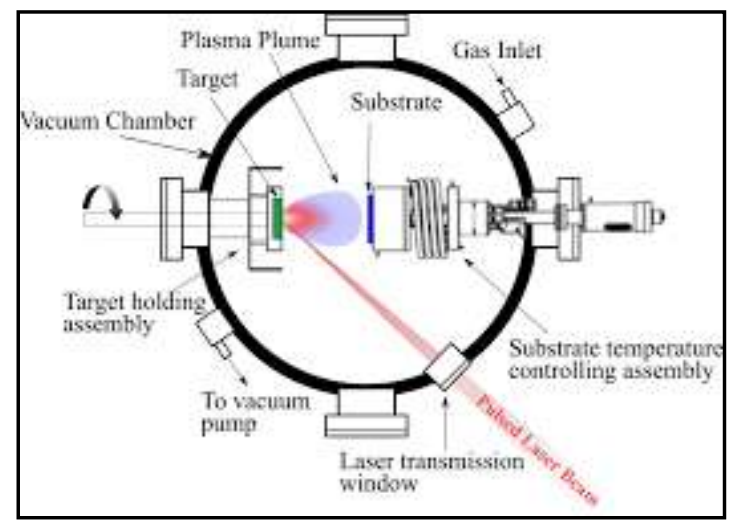

Fig. 1 Schematic diagram of Experimental Setup

\section{Results And Discussion}

The XRD of $\left(\mathrm{TiO}_{2}\right)_{1-\mathrm{x}}(\mathrm{CdO})_{\mathrm{x}}$ thin films deposited on glass substrate prepared by PLD. Fig.(2) shows that the XRD patterns of $\left(\mathrm{TiO}_{2}\right)_{1-\mathrm{x}}(\mathrm{CdO})_{\mathrm{x}}$ thin films after annealed to temperature of $500 \mathrm{~K}$ it can observed that the films show a polycrystalline film, with tetragonal structure for $\mathrm{TiO} 2$ and formation of Anatase phase and many peaks (101), (004) and (200) were appear when increasing of $\mathrm{CdO}$ concentration a new peak is appeared for $\mathrm{CdO}$, for concentration of $(0.1 \%, 0.3 \%, 0.5 \%$ and $1 \%)$ of $\mathrm{CdO}$ for intensities of (111), (200), (220) and (311) with cubic structure, which agree with (ASTM) card.

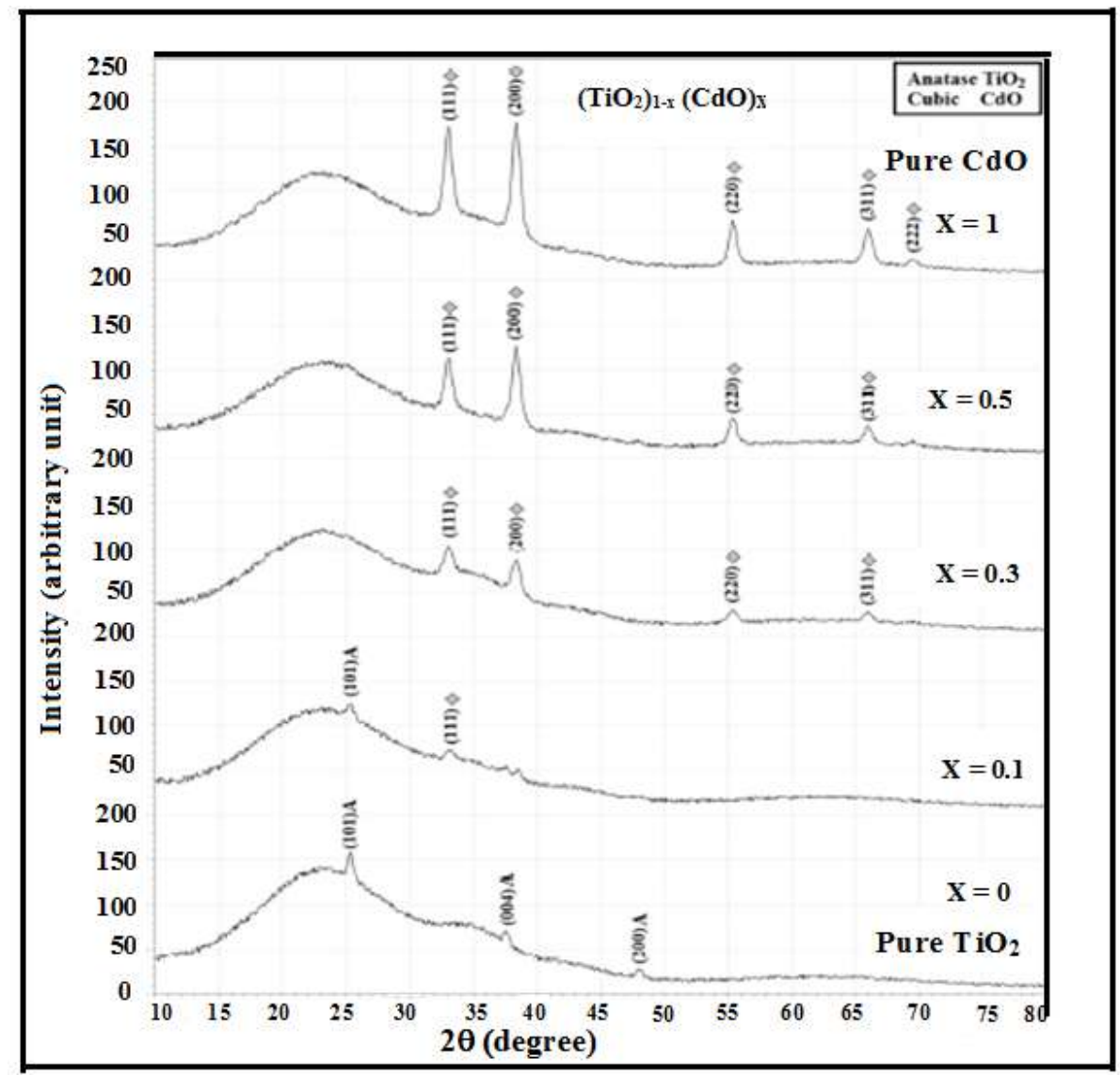

Fig.(2) X-Ray Diffraction for (TiO2) ${ }_{1-\mathrm{x}}(\mathrm{CdO})_{\mathrm{x}}$ Thin Films at $500 \mathrm{k}$

The optical properties of $(\mathrm{TiO} 2) 1-\mathrm{x}(\mathrm{CdO}) \mathrm{x}$ films grown on glass substrate which involve the transmittance, absorption coefficient, the optical energy gap and Refractive index Were studied the effect of the $\mathrm{CdO}$ content on optical properties of ( $\mathrm{TiO} 2) 1-\mathrm{x}(\mathrm{CdO}) \mathrm{x}$ films prepared by (PLD) were investigated.

Fig. (3) Shows the transmission spectrum as a function wavelength have been determined using UVVisible transmission spectrum in the spectral range (320-1100) $\mathrm{nm}$. It can be observed from this Fig(3) that the transmission spectrum shifts to longer wavelengths with increasing of different concentrations ratios. It is 
obvious that the transmission increases with increasing of annealing temperature and this may be due to improving the crystallite size which means a decrease in the reflection and absorption that occurs due to increase of annealing temperature. in the other hand increases in the absorbance and this is due to create levels centers inside the energy which is considered as traps centers leads to increase in the absorbance. The behavior of the transmission spectra is opposite completely to that of the absorption spectra.

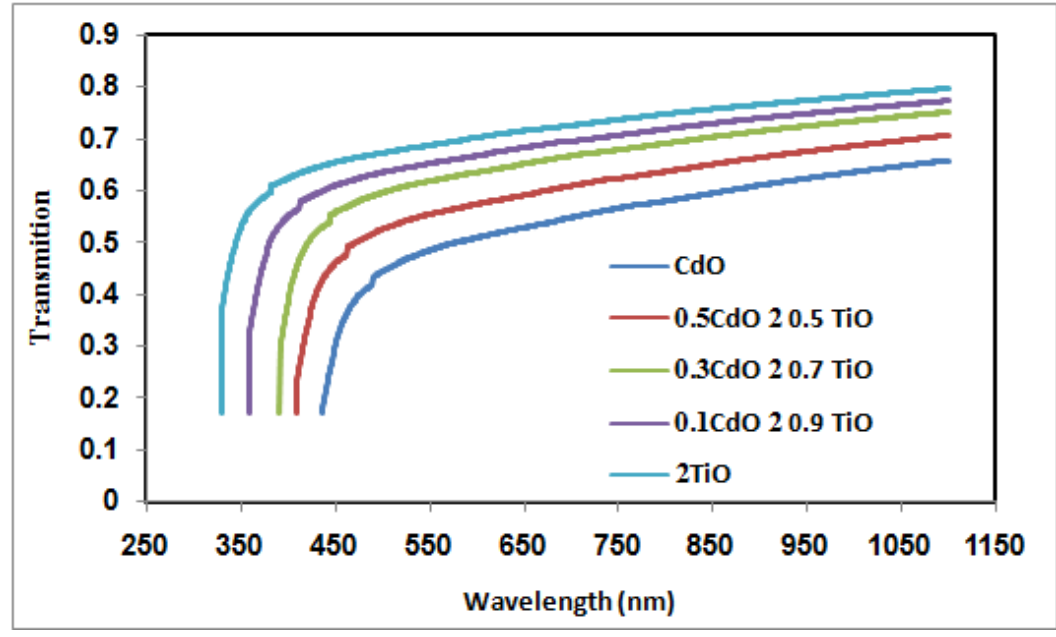

Fig.(3): The transmission spectra of $(\mathrm{TiO2})_{1-\mathrm{x}}(\mathrm{CdO})_{\mathrm{x}}$ thin films annealed at $\mathrm{Ta}=500 \mathrm{k}$

The absorption coefficient $\alpha$ was determined from the region of high absorption at the fundamental absorption edge of the film. The variation of the absorption coefficient versus the wavelength. It can be observed from this Fig(4) that the absorption coefficient shifts to longer wavelengths with increasing of different concentrations ratios of $\mathrm{CdO}$ at annealing temperatures $\left(\mathrm{T}_{\mathrm{a}}\right)$ equal to $500 \mathrm{k}$ of the $\left(\mathrm{TiO}_{2}\right)_{1-\mathrm{x}}(\mathrm{CdO})_{\mathrm{x}}$.

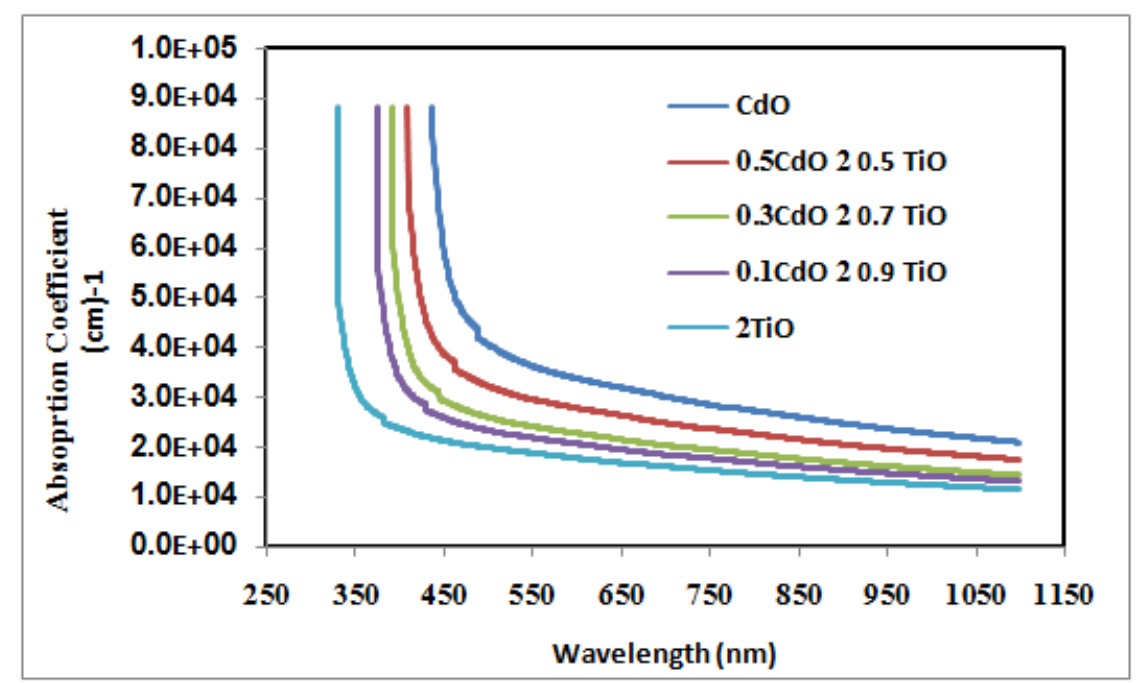

Fig.(4) : Variation of absorption coefficient as a function of wavelength for $(\mathrm{TiO} 2)_{1-\mathrm{x}}(\mathrm{CdO})_{\mathrm{x}}$ films at $\mathrm{Ta}=500 \mathrm{k}$

The direct optical energy gaps value $\left(\mathrm{E}_{g}^{o p t}\right.$ ) for of $(\mathbf{T i O 2})_{1-\mathbf{x}}(\mathbf{C d O})_{\mathbf{x}}$ films have been determined. A plot of $(\alpha h v)^{2}$ versus hv for of (TiO2) $)_{1-\mathbf{x}}(\mathbf{C d O})_{\mathbf{x}}$ with with increasing of different concentrations ratios of $\mathrm{CdO}$ at annealing temperatures $\left(\mathrm{T}_{\mathrm{a}}\right)$ equal to $500 \mathrm{k}$ of the $\left(\mathrm{TiO}_{2}\right)_{1-\mathrm{x}}(\mathrm{CdO})_{\mathrm{x}}$ is shown in Fig.(5).The plot is linear indicating the direct band gap of the films. Extrapolation of the linear of the line to the hv axis gives the band gap.The value of the optical energy gap decreases with increasing of different concentrations ratios of $\mathrm{CdO}$ at $\mathrm{Ta}=500 \mathrm{k}$. The optical energy gap values $\left(\mathrm{E}_{\mathrm{g}}\right)$ for of $(\mathbf{T i O 2})_{1-\mathbf{x}}(\mathbf{C d O})_{\mathbf{x}}$ films have been determined by using Tauc equation which is used to find the type of the optical transition by plotting the relations $(\alpha h v)^{1 / 2}$ versus photon energy (hv) and select the optimum linear part. It is found that the relation for $\mathrm{r}=1 / 2$ yields linear dependence. The extrapolation i.e. $\mathrm{E}_{\mathrm{g}}$, of the portion at $(\alpha=0)$. The value of optical energy gap decrease with increasing of different concentrations ratios of $\mathrm{CdO}$ at $\mathrm{Ta}=500 \mathrm{k}$ for all samples. 


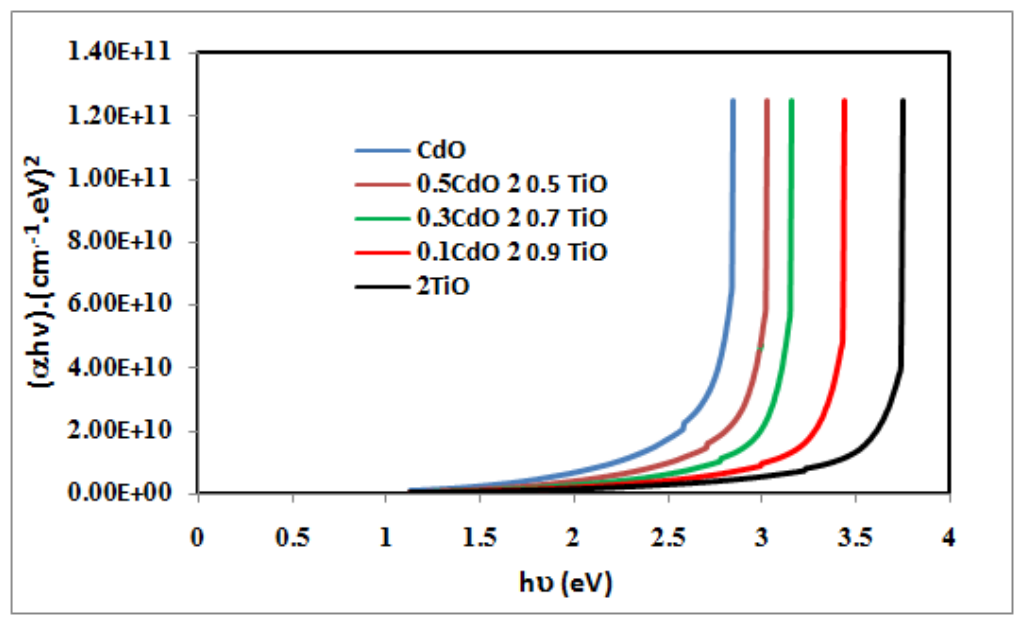

Fig.(5) : $(\alpha h v)^{2}$ as a function of $h v$ for $(\mathrm{TiO2})_{1-\mathrm{x}}(\mathrm{CdO})_{\mathrm{x}}$ films at $\mathrm{Ta}=500 \mathrm{k}$

Fig (6) Shows the variation in refractive index with wavelength for $(\mathbf{T i O 2})_{1-\mathbf{x}}(\mathbf{C d O})_{\mathrm{x}}$ films in the wavelength range of(320-1100)nm for annealing temperature (500)k and with increasing of different concentrations ratios of $\mathrm{CdO}$.It is observed that the refractive index, in general ,increases slightly with increases of concentration. This result can be explained by an increases in the density of the film due to better packing and increased crystalline.

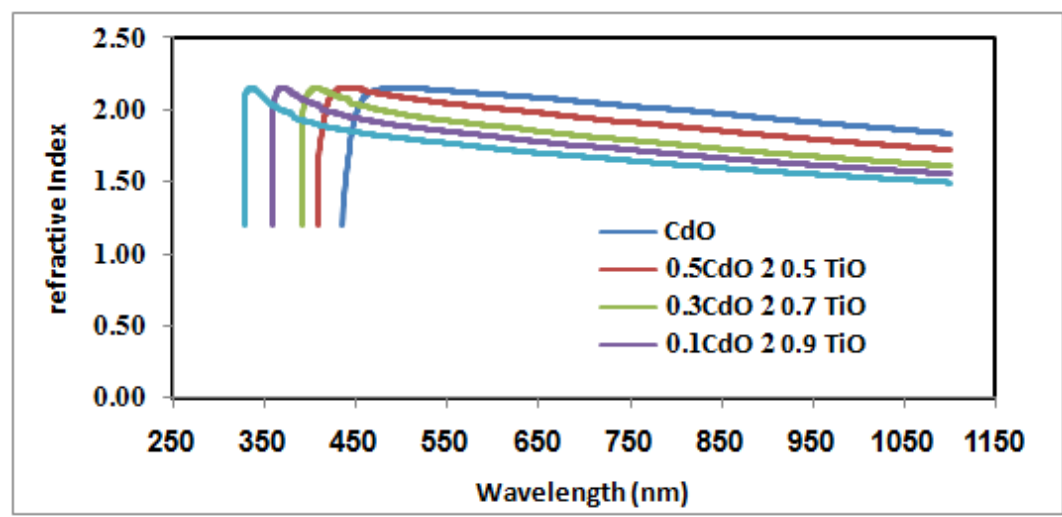

Fig.(6) : Variation of Refractive Index as a function of wavelength for $(\mathrm{TiO2})_{1-\mathrm{x}}(\mathrm{CdO})_{\mathrm{x}}$ films at $\mathrm{Ta}=500 \mathrm{k}$

\section{Conclusion}

This study focused on the effect of concentration ratio of $\mathrm{CdO}$ on phase transformation and optical properties of the $\left(\mathrm{TiO}_{2}\right)_{1-\mathrm{x}}(\mathrm{CdO})_{\mathrm{x}}$ thin films. The XRD pattern of the films show a polycrystalline film, with tetragonal structure for $\mathrm{TiO} 2$ and formation of Anatase phase and many peaks when increasing of $\mathrm{CdO}$ concentration a new peak is appearedfor $\mathrm{CdO}$, for concentration of $(0.1 \%, 0.3 \%, 0.5 \%$ and $1 \%)$ of $\mathrm{CdO}$ for intensities of (111), (200), (220) and (311) with cubic structure. while optical properties of thin films it can observedshifts to longer wavelengths with increasing of different concentrations ratios of $\mathrm{CdO}$ at annealing temperatures $\left(\mathrm{T}_{\mathrm{a}}\right)$ equal to $500 \mathrm{k}$

\section{References}

[1] H. M. Christen, G. Eres, J. Phys.: Condens. Matter 20 (2008) 264

[2] Chopra K. L. and Ranyan Das S., Thin Film Solar Cells, Plenum Press, New York (1993).

[3] Chopra K. L., Major S. and Pandya D. K., Thin Solid Films 102, 1 (1983).

[4] J. L. Vossen, in G. Hass, M.H. Francombe and R. W. Hoffman (eds.), Physics of Thin Solid Films, Academic Press. N. Y. (1977), p. 1.

[5] T. K. Subrayaman, B. Radna Krishna, S. Uthanna, B. S. Naidu and P. J. Reddy, Vacuum 48, 565 (1997).

[6] Z. M. Jarzberzki, Oxide Semiconductors, B. R. Pamplin (ed.), Pergamon Press. London (1973), p. 239.

[7] Z. A. Shukri, L.S. Yip, C. X. Qui, I. Shih and C. H. Champness, Tech. Digest of the 7th International Science and Engineering Conference, Nagoya Japan (1993), p.409.

[8] Shih, C. H. Champness, and N. Liria, Solar Cells, 7, 327 (1982-1983) 